ECOLOGICA, Vol. 28, No 101 (2021), 22-28

https://doi.org/10.18485/ecologica.2021.28.101.5

Originalni naučni rad

UDC:614.75:658.788.4

\title{
Pakovanje opasnih materija u propisanu ambalažu
}

\section{Packaging of hazardous materials in the prescribed ambalage}

\author{
Siniša Sremac ${ }^{1}$, Dragan Smiljanić2 \\ 1,2Fakultet tehničkih nauka, Univerzitet u Novom Sadu, Trg Dositeja Obradovića 6, Novi Sad, Srbija \\ ${ }^{1,2}$ Faculty of Technical Sciences, University of Novi Sad, Trg Dositeja Obradovića 6, Novi Sad, Serbia
}

Rad primljen: 20.01.2021, Rad prihvaćen: 26.02.2021.

Sažetak: Bez obzira na opasnosti koje prouzrokuju, opasne materije nalaze sve veću primenu kako u privredi, tako i u svakodnevnom životu. Godišnje se proizvode značajne količine opasnih materija i time stvaraju visoki rizici po život i zdravlje ljudi, životnu sredinu i materijalna dobra. Jedan od načina za smanjenje rizika je upotreba sertifikovane ambalaže za pakovanje opasnih materija. Standardi koje mora ispuniti ambalaža za opasne materije prevazilaze zahteve koji se postavljaju pred transport drugih vrsta robe. Neophodno je ispuniti sve bezbednosne zahteve definisane u odgovarajućim pravnim aktima koji se odnose na pakovanje, transport i distribuciju ove vrste robe. $U$ oblasti pakovanja opasnih materija to se odnosi na upotrebu odgovarajuće ambalaže za datu materiju, ocena usaglašenosti i periodično kontrolisanje ambalaže, kao i adekvatno obeležavanje i označavanje ambalaže.

Ključne reči: sertifikovana ambalaža, opasne materije, obeležavanje i označavanje ambalaže.

\begin{abstract}
Regardless of the dangers they cause, dangerous substances are increasingly used both in the economy and in everyday life. Significant quantities of dangerous substances are produced annually, thus creating high risks to human life and health, the environment and material goods. One way to reduce the risk is to use certified packaging for packaging hazardous materials. The standards that packaging for dangerous substances must meet exceed the requirements set for the transport of other types of goods. It is necessary to meet all safety requirements defined in the relevant legal acts relating to the packaging, transport and distribution of this type of goods. In the field of packaging of dangerous substances, this refers to the use of appropriate packaging for a particular substance, conformity assessment and periodic inspection of packaging, as well as adequate labelling and marking of packaging.
\end{abstract}

Keywords: certified packaging, dangerous substances, marking and labelling of packaging.

10rcid.org/0000-0002-3641-5107, e-mail: sremacs@uns.ac.rs

2orcid.org/0000-0002-3609-3283, e-mail: targija996@gmail.com 


\section{UVOD / INTRODUCTION}

Opasne materije su sirovine, poluproizvodi ili gotovi proizvodi koji zbog karakterističnog hemijskog sastava i određenih svojstava imaju niz poželjnih osobina za svrsishodnu upotrebu. Međutim, u nekontrolisanim uslovima mogu da izazovu posledice koje su opasne i štetne za ljude, životinje, materijalna dobra, vodotokove, vegetaciju, generalno za čitav ekosistem na mikro, meta ili na makro nivou.

Ambalaža za opasne materije mora biti dovoljno jaka, da izdrži udare i naprezanja, koji mogu nastati pod uobičajenim uslovima transporta i skladištenja, uključujući pretovar između transportnih jedinica i manipulisanje paletama i jedinicama pakovanja. Takođe, mora se voditi računa o vrsti materijala od kojeg je ambalaža izrađena, kako ne bi došlo do hemijske reakcije i oštećenja, a samim tim do curenja ili izlivanja opasne materije.

Bez obzira na opasnosti koje prouzrokuju, opasne materije nalaze sve veću primenu kako u privredi, tako i u svakodnevnom životu (Tepić i dr., 2019). Svojstva ovih materija su takva, da samim postojanjem, upotrebom ili korišćenjem stvaraju povećanu opasnost za okolinu. Razorna moć pojednih opasnih materija je takva da može izazvati katastrofalne posledice (Tepić i dr., 2020).

Jedan od načina da se smanje potencijalni rizici jeste primena važećih propisa i upotreba propisane ambalaže $u$ transportu opasne robe. To je tehnološki zahtevan zadatak, jer standardi i zahtevi koje mora ispuniti ambalaža prevazilaze standarde i zahteve koji se postavljaju pred transport ostalih vrsta robe (Ožegović i dr., 2017). Zato su generacije stručnjaka raznih grana, pre svega hemičara $i$ inženjera svih potrebnih profila, permanentno razvijali tehničko-tehnološke sisteme za bezbedan transport opasne robe, između ostalog i pakovanje opasnih materija. Danas je to jedna od normativno najuređenijih oblasti na međunarodnom nivou (Pamučar i dr., 2019).

U cilju bezbedne otpreme opasnih materija ili predmeta upakovanih u ambalažu, neophodno je ispoštovati sve zahteve koji su propisani za pakovanje opasnih materija. Ambalaža za prevoz opasnih materija mora da ispunjava sledeće zahteve: adekvatnu zaptivenost, otpornost na mehaničko dejstvo materija i otpornost na mehaničke udare i lomljivost.

\section{BEZBEDNOSNI ZAHTEVI ZA UPOTREBU AMBALAŽE / SAFETY REQUIREMENTS FOR THE USE OF AMBALAGE}

$U$ nacionalnim propisima Republike Srbije, transport i pakovanje opasnih materija je regulisano Zakonom o transportu opasne robe (SI. Glasnik
R. Srbije, 2016, 2018) i podzakonskim aktima. Članom 4. ovog zakona je predviđeno da se transport opasne robe na teritoriji Republike Srbije obavlja u skladu sa odredbama potvrđenih međunarodnih ugovora ADR, RID i ADN.

Da bi broj akcidenata sa opasnim materijama bio što manji, kao i njihove posledice, bilo je neophodno utvrditi određena pravila. Sa tim ciljem Ujedinjene nacije (UN) su 1954. godine formirale ekspertski tim koji je dao preporuke za kreiranje jedinstvenih kriterijuma u oblasti opasnih materija, koji se odnose na obeležavanje, klasifikaciju, vozila, ambalažu i pakovanje, dozvole i dr. Ekonomska komisija UN za Evropu (UNECE) - Odbor za kopneni transport je nadležan za donošenje ovih propisa, koje su u formi sporazuma prihvatale i potvrđivale zainteresovane države od 1957. godine. U prilogu ovih sporazuma, Tehničkim propisima su utvrđeni uslovi, norme, standardi i pravila za siguran međunarodni transport opasne robe drumom - ADR (UNECE, 2021) i železnicom - RID (OTIF, 2021), kao i unutrašnjim plovnim putevima ADN (OTIF, 2021).

Tehničkim propisima obuhvaćeni su i bezbednosni zahtevi za pakovanje opasnih materija u odgovarajuću ambalažu (slika 1). Ambalaža za opasne materije je jedna ili više posuda i svi drugi sastavni delovi, druge komponente ili materijali, koji su potrebni da bi posuda ispunila svoju funkciju rezervoara i sigurnosnu funkciju za prihvatanje i sigurno čuvanje sadržaja (Sremac i dr., 2017). Delovi ambalaže koji dolaze u neposredni dodir sa hemikalijom ne smeju hemijskim ili drugim reakcijama da budu oštećeni.

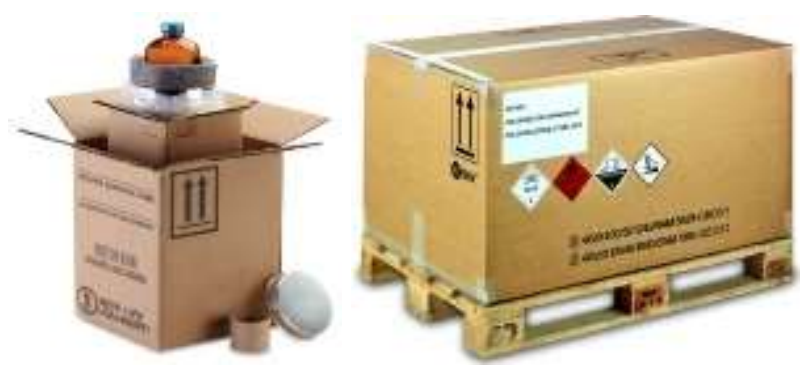

Slika 1 - Ambalaža za opasne materije

Figure 1 - Packaging for dangerous substances

Na teritoriji Republike Srbije, za transport opasne robe, može da se koristi samo ambalaža (Zakon o transportu opasne robe, SI. Glasnik R. Srbije, 2016, 2018):

- koja je odgovarajuća po tehničkim karakteristikama za datu količinu i date osobine opasne robe koja se u pakuje/puni u ambalažu, odnosno koja ispunjava i druge zahteve bezbednosti prema propisima ADR/RID/ ADN, 
- za koju je sprovedeno ocenjivanje usaglašenosti u skladu sa zahtevima ADR/RID/ADN,

- koja je obeležena i označena u skladu sa ADR/RID/ADN i

- za koju postoji važeća isprava o periodičnom kontrolisanju u skladu sa ADR/RID/ADN.

Odgovarajuća ambalaža za opasne materije / Appropriate ambalage for hazardous materials

Osnovno uputstvo za upotrebu ADR-a i pakovanje opasne materije $u$ ambalažu čini tabela $A$ poglavlja 3.2 ADR. Tabela sadrži spisak opasne robe u numeričkom redosled uprema UN brojevima. Po pravilu, svaki red tabele A obrađuje materiju koja je obuhvaćena određenim UN brojem. Određivanjem UN broja opasne materije, tabela obezbeđuje unakrsno povezivanje sa posebnim zahtevim akoji se moraju ispuniti za pakovanje i transport date materije, kao i sa poglavljima ili odeljcima u kojima se mogunaći konkretni zahtevi. U tabeli 1 dat je izvod iz Tabele A poglavlja 3.2 ADR koji se odnosi na upotrebu odgovarjuće ambalaže za opasnu materiju sa UN brojem 1202.

Tabela 1 - Izvod izTabele A u poglavlja 3.2 ADR-a za UN 1202 sa zahtevima za ambalažu i pakovanje Table 1 - Except from Table A in Chapter 3.2 of the ADR for UN 1202 with requirements for ambalage and packaging

\begin{tabular}{|c|c|c|c|c|c|c|}
\hline \multirow{3}{*}{$\begin{array}{l}\text { UN } \\
\text { broj }\end{array}$} & \multirow{2}{*}{ Naziv i opis } & \multirow[b]{2}{*}{$\begin{array}{c}\text { Grupa } \\
\text { pakovanja }\end{array}$} & \multirow[b]{2}{*}{$\begin{array}{c}\text { Listice } \\
\text { opasnosti }\end{array}$} & \multicolumn{3}{|c|}{ Ambalaža } \\
\hline & & & & $\begin{array}{l}\text { Uputstva za } \\
\text { pakovanje }\end{array}$ & $\begin{array}{l}\text { Posebne } \\
\text { odredbe za } \\
\text { pakovanie }\end{array}$ & $\begin{array}{l}\text { Odredbe za } \\
\text { zajedničko } \\
\text { pakovanie }\end{array}$ \\
\hline & 3.1 .2 & 2.1.1.3 & 5.2 .2 & 4.1 .4 & & \\
\hline (1) & (2) & (4) & (5) & (8) & (9a) & $(9 b)$ \\
\hline 1202 & $\begin{array}{l}\text { DIZEL GORIVO ili GAZOL ili ULJE ZA } \\
\text { LOŽENJE, LAKO (tačka paljenja najviše } \\
60^{\circ} \mathrm{C} \text { ) }\end{array}$ & III & 3 & $\begin{array}{ll}= & P 001 \\
= & \text { IBC03 } \\
= & \text { LP01 } \\
& \text { R001 }\end{array}$ & & MP19 \\
\hline
\end{tabular}

Kolona (1) sadrži UN broj za:

- $\quad$ opasnu materiju ili predmet, ako je materija ili predmet svrstana u sopstveni specifični UN broj ili

- $\quad$ naziv po vrstama ili naziv n.d.n., u koje se svrstavaju opasne materije i predmeti koji nisu poimenično navedeni u skladu sa kriterijumima Dela 2 za klasifikaciju opasnih materija.

Kolona (2) sadrži naziv materije, ispisan velikim slovima, ako je materiji dodeljen sopstveni specifičan UN broj, ili naziv po vrstama ili naziv n.d.n., u koji je svrstana opasna materija ili predmet u skladu s kriterijumima Dela 2. Ovaj naziv se mora koristiti kao zvanični naziv za transport, ili po potrebi, kao deo zvaničnog naziva za transport.

Kolona (4) sadrži broj grupe pakovanja (I, II ili III) u koju je svrstana opasna materija. Ovi brojevi grupe pakovanja se dodeljuju na osnovu postupaka i kriterijuma Dela 2 ADR. Određene materije nisu svrstane ni u jednu grupu pakovanja. Materije se u svrhu pakovanja na osnovu njihovog stepena opasnosti svrstavaju u grupe pakovanja:

- I - materije s visokim stepenom opasnosti,

- II - materije sa srednjim stepenom opasnosti i

- $\quad$ III - materije s malim stepenom opasnosti.
Kolona (8) sadrži alfanumeričke kôdove za primenu uputstava za ambalažu:

- Alfanumerički kôdovi koji počinju slovom "P", odnose se na uputstva za pakovanje za ambalažu i posude (izuzev IBC i velike ambalaže), dok se alfanumerički kôdovi koji počinju slovom "R" odnose na uputstva za ambalažu od tankog lima. Ako kolona (8) ne sadrži nikakav kôd koji počinje slovima "P" ili "R", data opasna roba se ne može transportovati u ambalaži;

- $\quad$ Alfanumerički kôdovi koji počinju slovima "IBC" odnose se na uputstva za pakovanje za IBC. Ako kolona (8) ne sadrži nikakav kôd koji počinje slovima "IBC", data opasna roba se ne može transportovati u IBC ambalaži;

- Alfanumerički kôdovi koji počinju slovima "LP" odnose se na uputstva za pakovanje za veliku ambalažu. Ako kolona (8) ne sadrži nikakve kôdove koji počinju slovima "LP", data opasna roba se ne može transportovati u velikoj ambalaži;

Kolona (9a) sadrži alfanumeričke kôdove primenjivih posebnih odredbi za pakovanje:

- $\quad$ Alfanumerički kôdovi koji počinju slovima "PP" ili "RR" odnose se na posebne dodatne odredbe za pakovanje u am- 
balažu i posude kojih se treba pridržavati (izuzev IBC i velike ambalaže). Ako kolona (9a) ne sadrži nikakve kôdove koji počinju slovima "PP" ili "RR", ne važe nikakve posebne odredbe za pakovanje;

- Alfanumerički kôdovi koji počinju slovom "B" ili slovima "BB" odnose se na posebne dodatne odredbe za IBC kojih se treba pridržavati. Ako kolona (9a) ne sadrži nikakav kôd koji počinje slovom "B", ne važe posebne odredbe za pakovanje;

- Alfanumerički kôdovi koji počinju slovom "L" ili slovima "LL" odnose se na posebne dodatne odredbe za pakovanje u veliku ambalažu, kojih se treba pridržavati. Ako kolona (9a) ne sadrži nikakav kôd koji počinje slovom "L" ili slovima "LL", ne važe posebne odredbe.

Kolona (9b) sadrži alfanumeričke kôdove koji počinju slovima "MP" primenjivih posebnih odredbi za zajedničko pakovanje. Ako ova kolona ne sadrži nikakav kôd, koji počinje slovima "MP", važe samo opšte odredbe za zajedničko pakovanje.

\section{Ocena usaglašenosti i periodično kontrolisanje ambalaže / Conformity assessment and periodic inspection of ambalage}

Ocena usaglašenosti je postupak ispitivanja usaglašenosti ambalaže koji se odnosi na odobrenje tipa, kontrolu proizvodnje i prvo kontrolisanje (ADR, 2021). Postupak ocenjivanja usaglašenosti i periodična kontrolisanja izvršava nadležni organ, njegovo ovlašćeno lice ili najčešće imenovano kontrolno telo. Nadležni organ mora da obezbedi nadzor nad kontrolnim telima da li ispunjavaju zahteve i postupke koji su utvrđeni propisima.

Imenovano telo koje sprovodi ispitivanje i kontrolisanje ambalaže mora imati odobrenje nadležnog organa i:

- raspolagati adekvatnim, obučenim, kompetentnim i iskusnim osobljem koje na zadovoljavajući način može da vrši svoje tehničke poslove,

- imati pristup odgovarajućim i adekvatnim uređajima i opremi,

- $\quad$ biti nezavisno u svom radu i oslobođeno od uticaja koji bi mogli da ga sprečavaju u tome,

- $\quad$ upravljati dokumentovanim sistemom obezbeđenja kvaliteta,

- obezbediti da se periodična kontrolisanja i ispitivanja sprovode u skladu s propisima $i$
- održavati efikasan i adekvatan sistem izveštavanja i evidentiranja.

Usaglašenost ambalaže se utvrđuje prema propisima nadležnog organa u trenutku proizvodnje od strane kontrolnog tela. Tehnička dokumentacija mora da obuhvati kompletnu specifikaciju za projektovanje i izradu i kompletnu dokumentaciju proizvodnje i ispitivanja (Sremac i dr., 2016).

Nakon izdavanja odobrenja od strane kontrolnog tela, proizvođač mora dati izjavu o usaglašenosti sa tipom konstrukcije shodno uverenju. Stavljanje sertifikacionih obeležja smatra se izjavom da ambalaža odgovara standardima koji se primenjuju, kao i zahtevima sistema ocenjivanja usaglašenosti i ADR. Na svaku ambalažu za koju je izdato odobrenje, kontrolno telo ili proizvođač koga je odredilo kontrolno telo mora da stavi sertifikaciona obeležja za ambalažu (slika 2).

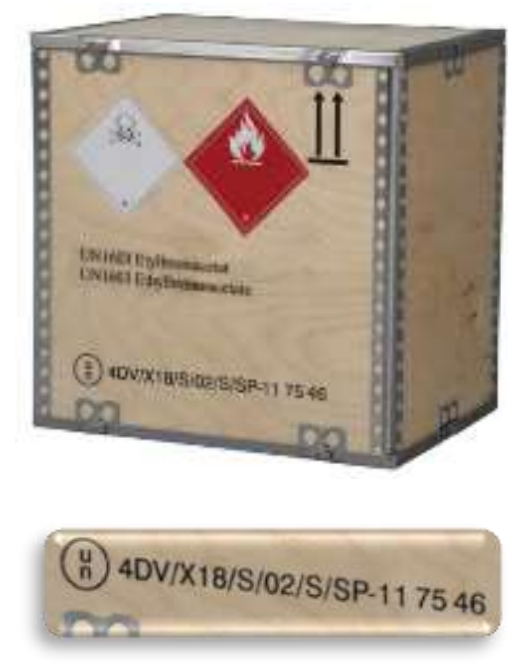

Slika 2 - Sertifikaciono obeležje na ambalaži za
opasne materije

Figure 2 - Certification mark on the packaging for dangerous substances

Sertifikacioni kod na ambalaži svakako najviše znači onima koji rukuju sa istom. Informacija u vezi sa sertifikacionim kodom važna je za proizvođača, korisnika ambalaže i obnavljača kako bi se utvrdilo da ambalaža ispunjava propisane uslove (Smiljanić i dr., 2017).

Prilikom izrade ambalaže, proizvođač je dužan da unese sertifikacioni kod, sa podacima koji su propisani u ADR-u. Podaci se utisnuti ili nalepljeni na bočnoj strani ambalaže. Značenje sertifikacionog koda ambalaže prikazano je na slici 3 .

$\mathrm{Na}$ slici 4 je prikazan primer sertifikacionog obeležja na čeličnom buretu sa neodvojivim poklopcem, za pakovanje opasnih materija. 


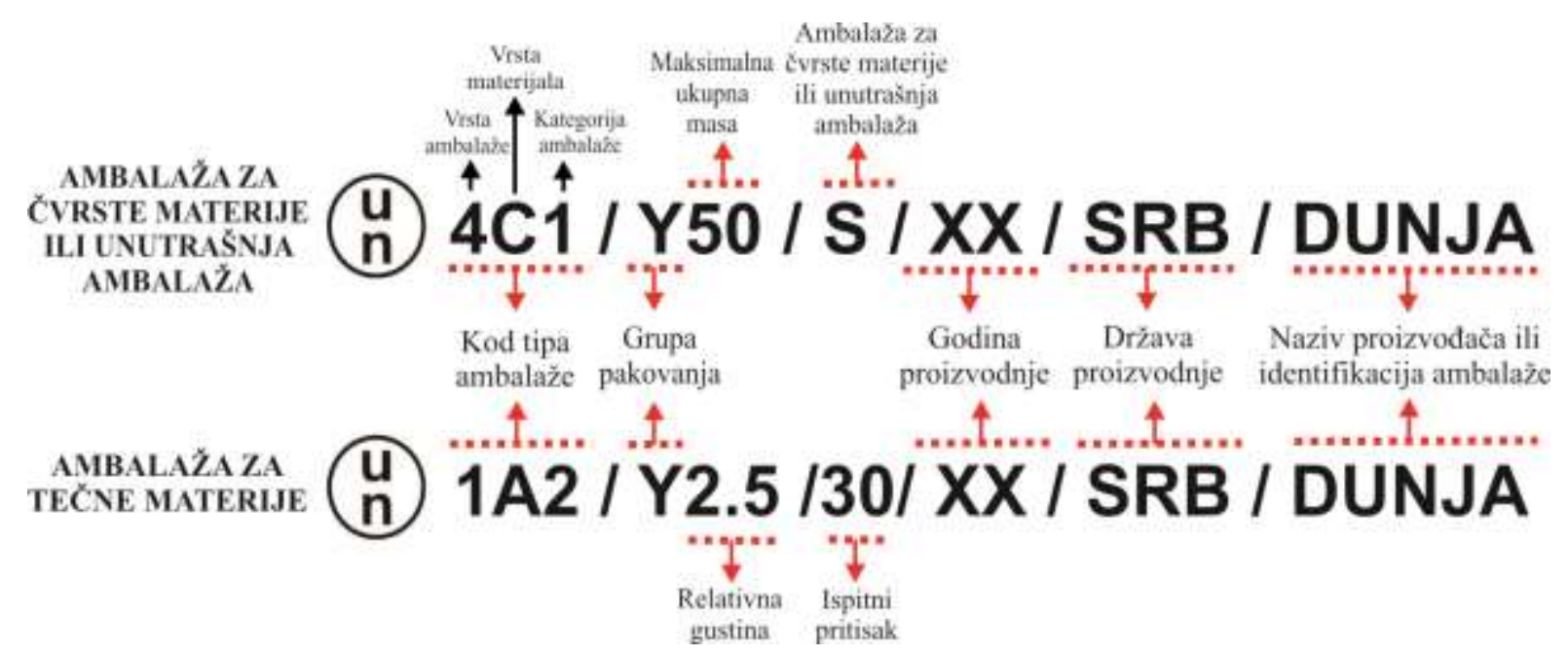

Slika 3 - Značenje sertifikacionog obeležja na ambalaži za opasne materije

Figure 3 - Significance of the certification mark on the packaging for dangerous substances

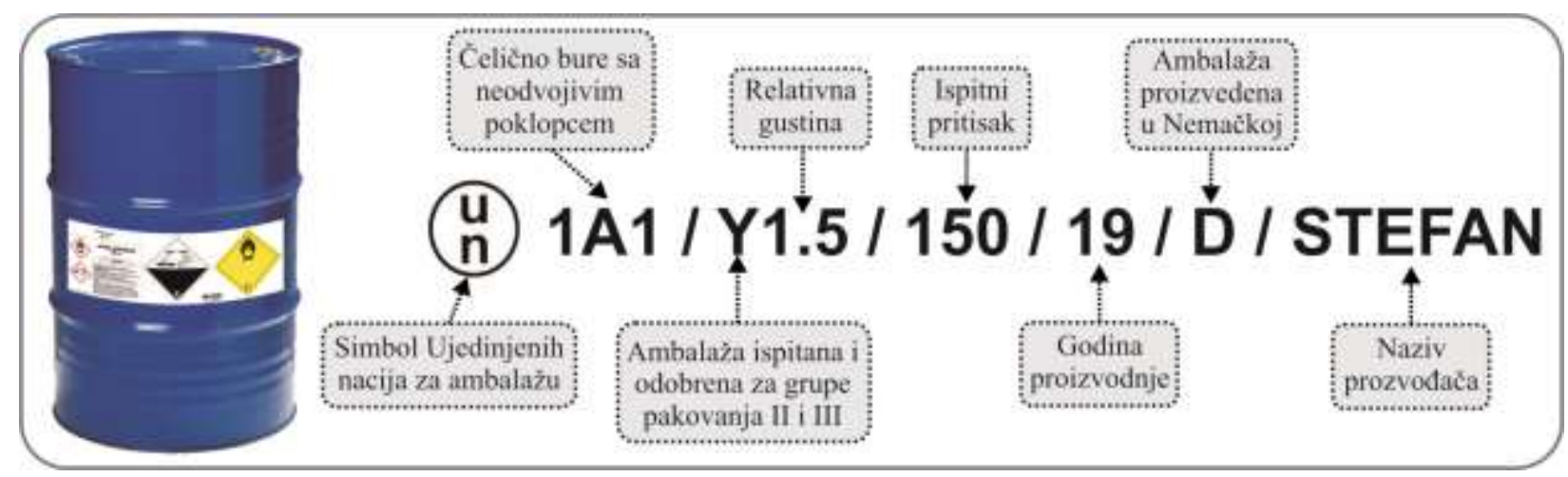

Slika 4 - Sertifikaciono obeležje na čeličnom buretu za opasne materije

Figure 4 - Certification mark on a steel barrel for dangerous substances

Obnavljač ambalaže mora posle obnavljanja da stavi sledeća trajna obeležja na ambalažu i to po redosledu gde trajna obeležja prikazuju:

- oznaku države u kojoj je izvršeno obnavljanje,

- naziv obnavljača ili neka druga identifikacija ambalaže utvrđena od strane nadležnog organa $\mathrm{i}$

- godinu obnavljanja, slovo „R“ i za svaku ambalažu koja je uspešno podvrgnuta ispitivanju zaptivenosti dodatno slovo „L“.

Primer za obeležavanje obnovljene ambalaže je: 1A1/Y1.4/150/14/I/STASA/01RL.

\section{Obeležavanje i označavanje ambalaže / Marking and labeling of ambalages}

$U$ transportu opasne robe, ambalaža $s$ opasnom materijom se obeležava i označava kao komad za otpremu sa (slika 5):

- UN brojem,
- listicama opasnosti i

- sertifikacionim kodom ambalaže.

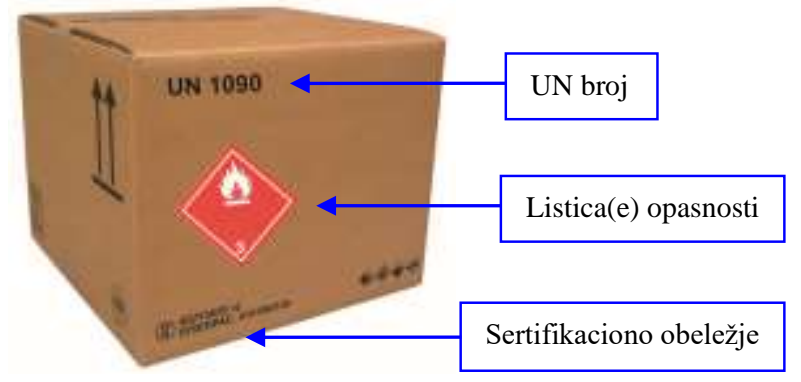

Slika 5 - Propisno obeležena i označena ambalaža sa opasnom materijom

Figure 5 - Properly marked and labeled packaging with dangerous material

Svaki komad za otpremu ambalaže treba da bude jasno i trajno obeležen UN brojem opasne materije koju sadrži, ispred kojeg se nalaze slova „UN“. UN broj i slova „UN“ moraju imati visinu od 
najmanje $12 \mathrm{~mm}$. UN broj je identifikacioni broj materije, kako bi rukovaoci bili upućeni o kojoj opasnoj materiji se radi.

U skladu sa datim UN brojem potrebno je postaviti i odgovarajuće listice opasnosti propisane $u$ koloni (5) Tabele A poglavlja 3.2. Na ovaj način ukazuje se na moguću opasnost u slučaju nepravilnog rukovanja ili vanrednog događaja. Umesto listica opasnosti smeju se staviti i neizbrisiva obeležja opasnosti koja u potpunosti odgovaraju zahtevanim obrascima. Jedino kod IBC ambalaže sa zapreminom od preko 450 litara i velike ambalaže moraju se postaviti obeležja na dve suprotne strane.

Svaka listica opasnosti mora:

- da bude stavljena na istu površinu ambalaže, ukoliko to dozvoljavaju dimenzije ambalaže,

- da bude postavljena na ambalažu tako da ne budu prekrivene niti skrivene nekim delom ambalaže, nekim delom postavljenim na ambalažu, nekom drugom listicom opasnosti ili nekim obeležjem i

- da bude stavljena blizu jedna pored druge, ako se zahteva više od jedne listice opasnosti.

\section{ZAKLJUČAK / CONCLUSION}

$U$ cilju bezbedne otpreme opasnih materija $u$ ambalaži, neophodno je ispoštovati sve zahteve koji su propisani za pakovanje opasnih materija. Propisana ambalaža za određenu opasnu materiju mora da poseduje sertifikacioni kod ambalaže, kojim se dokazuje vrsta ambalaže, zemlja porekla i datum proizvodnje. Opasnost koja može biti posledica neadekvatnog pakovanja i rukovanja opasnom robom je usko povezana sa vrstom i kvalitetom ambalaže, načinom pakovanja i obeležavanjem ambalaže.

Analiza stanja u pogledu upotrebe propisane ambalaže ukazuje na potrebu pridržavanja odredbi ADR i Zakona o transportu opasne robe. Da bi se transport opasne robe u potpunosti uskladio sa važećim propisima, potrebno je preduzeti sve mere adekvatne organizacije transporta i preventivne mere ispitivanja kvaliteta ambalaže od strane akreditovanih laboratorija. Jedna od mera za korišćenje odgovarajuće i sertifikovane ambalaže je kontrola primene važećih propisa i angažovanje propisanih stručnih lica. Savetnik za bezbednost u transportu opasne robe je lice koje u privrednom društvu, drugom pravnom licu ili kod preduzetnika obavlja poslove kojima se obezbeđuje primena propisa u transportu opasne robe, organizuje transport opasne robe i povećava bezbednost.

\section{Zahvalnica / Acknowledgment}

Rezultati prikazani u ovom radu su deo istraživanja projekta "Primena savremenih didaktičkih alata u funkciji unapređenja saobraćajnog obrazovanja i naučno-istraživačkog rada", osnovanog od strane Departmana za saobraćaj Fakulteta tehničkih nauka u Novom Sadu, Univerzitet u Novom Sadu, Republika Srbija.

\section{LITERATURA / REFERENCES}

[1] European Agreement Concerning the International Carriage of Dangerous Goods by Inland Waterways - ADN, (2021). United Nations Economic Commission for Europe, Geneva, Switzerland.

[2] European Agreement concerning the International Carriage of Dangerous Goods by Road $A D R$, (2021). United Nations Economic Commission for Europe - UNECE, Geneva, Switzerland.

[3] Ožegović, B., Sremac, S., Arsić, T., Tepić, G., (2017). Organization of transportation of medical and clinical waste, VI International Symposium New Horizons 2017 of Transport and Communications, Doboj, Bosnia and Hercegovina, pp. 516-523.

[4] Pamučar, D., Sremac, S., Stević, Ž., Ćirović, G., Tomić, D., (2019). New multi-criteria LNN WASPAS model for evaluating the work of advisors in the transport of hazardous goods, Neural Computing and Applications, 31, 50455068.

[5] Regulation concerning the International Carriage of Dangerous Goods by Rail - RID, (2021), OTIF, Berne, Switzerland.

[6] Smiljanić, N., Arsić, T., Vukobratović, B., Sremac, S., (2017). Medical waste - solutions and dilemmas, 10th International scientific conference Crisis Management Days, Tuhelj, Croatia, pp. 772-779,.

[7] Sremac, S., Arsić. T., Smiljanić, N., Vukobratović, B., Stojić, G., (2017). Safety plans as a prevention in the transport of dangerous goods, VI International Symposium New Horizons 2017 of Transport and Communications, Doboj, Bosnia and Hercegovina, str. 97-102.

[8] Sremac, S., Arsić, T., Vukobratović, B., Smiljanić, N., Tepić, G., (2016). Justification of the usage of the approved packaging in the transport of dangerous goods, First International 
Conference Transport for Today's Society, Bitola, Severna Makedonija, pp. 264-270.

[9] Tepić, G., Sremac, S., Milisavljević, S., Tasić, N., Bogojević, B., (2019). Fukushima Daiichi accident caused by natural disaster, Ecologica, Vol. 26, No. 94, pp. 247-252.
[10] Tepić, G., Tasić, N., Sremac, S, Bogojević, B., (2020). loT u menadžmentu katastrofalnih događaja, Ecologica, Vol. 27, No. 97, str. 129-133.

[11] Zakon o transportu opasne robe, Službeni glasnik RS, br. 104/2016, 83/2018. 